\title{
Prevalence and patterns of birth defects among newborns in Southwestern Ethiopia: Retrospective study
}

Soressa Abebe Geneti ( $\sim$ abebe.soressa@gmail.com )

Addis Ababa University College of Health Sciences

Girmai Gebru

Addis Ababa University School of Medicine

Demisew Amenu

Jimma University College of Public Health and Medical Sciences

Lemessa Dube

Jimma University College of Public Health and Medical Sciences

Research article

Keywords: Prevalence, Birth defects, Ethiopia

Posted Date: December 23rd, 2019

DOl: https://doi.org/10.21203/rs.2.17559/v2

License: (c) (1) This work is licensed under a Creative Commons Attribution 4.0 International License.

Read Full License

Version of Record: A version of this preprint was published at Pan African Medical Journal on January 1st, 2021. See the published version at https://doi.org/10.11604/pamj.2021.40.248.25286. 


\section{Abstract}

Background : Intrauterine development can be considered as normal development as well as abnormal development. Abnormal development commonly called birth defects occur because of interference of normal development from genetic disorders, environmental factors and the combination of both genetic and environment factors during the critical period of embryogenesis. The present study aimed to evaluate the prevalence and patterns of birth defects at birth in Southwestern Ethiopia. Methods : Institutions based cross-sectional study design was used. Six hospitals were selected from the existing hospitals in southwestern Ethiopia purposively based on case load. The study was conducted from September 2011 to December 2015 during which 45,951 deliveries were attained. All records of births that were occurred in the selected hospitals during the study period were identified from medical records, to locate the birth defect records. Results : Twenty-one different birth defects were recorded. Of these, $49.6 \%$ of the birth defects recorded were Anencephaly and Hydrocephalus. Five types of birth defects namely: Anencephaly (25.0\%), Hydrocephalus (24.6\%), Spinal bifida (13.1\%), Meningomyelocele (7.1\%), and Umbilical hernia (4.8\%) accounted about three-fourth (75\%) of all recorded birth defects. The present study revealed that the prevalence of the birth defects at birth was found to be 5.5 per 1000 births. Among twenty one birth defects identified in this study, the neural tube defects were the most frequent with prevalence rate of 4.1 per 1000 birth followed by gastrointestinal defects ( 0.7 per 1000 births) Conclusions: As compared to other study, the prevalence of birth defect identified in the present study was found to be higher. The neural tube defects were the most prevalent with the frequency of 4.05 cases per 1000 . The present study also identified that nearly equal proportions of birth defect occurred among males and females newborns. The majority of the mother who gave birth to birth defects was younger than 35 years old. As the birth defect was found to be a main cases of infant mortality and morbidity, there need to an urgent interventions to control the cases.

\section{Background}

Intrauterine development can be considered as normal development as well as abnormal development. Abnormal development occurs because of interference of normal development from genetic disorders, environmental factors and the combination of both genetic and environment factors during the critical period of embryogenesis. These lead to abnormal cytogenesis, histogenesis and morphogenesis with which the neonate born with defect $[1,2]$

Congenital anomalies (CA) commonly called birth defect (BD) is structural as well as functional abnormality that present at birth and can be described in terms of four clinically significant types based upon the causes, timing, and extent of the developmental interference during prenatal life by teratologic agents [3]. These are malformation, disruption, deformation, and dysplasia [4, 5]. The World Health Organization (WHO) estimates that approximately 260,000 deaths (7\% of all neonatal deaths) globally were caused by BDs in 2004 [6]. It is estimated that the prevalence rates of birth defect is $4.7 \%$ in the developed countries, $5.6 \%$ in the middle-income countries, and $6.4 \%$ in the low-income country [7]. 
The incidence of CA varies among different ethnic groups [8]. Extensive literature is available on the incidence of CA in First-World countries and studies have also been done in several Third-World countries [8]. However, in Africa south of the Sahara, limited information is available on the incidence of CA, especially in the black population. Previous studies all had limitations in that they were either retrospective, performed on small sample numbers, or reported the frequency of a single abnormality or a few specific abnormalities [1].

$\mathrm{BD}$ is emerging as important prenatal problem contributing to the prenatal mortality and morbidity [9]. The differences between the frequency of the types of congenital malformation (CM) in different parts of this country and reports from other countries may be due to genetic background and geographic location, nutritional and socioeconomic differences [9]. CM begins to emerge as one of the major childhood health problems as well as a cause of infant mortality and morbidity throughout the world especially in developing countries [10]. In most cases, infants with malformation do not survive, more than $70 \%$ die in the first month of life [11, 12 - 15]

The frequency of BD in the developing countries including Ethiopia is underestimated because of the deficiencies in diagnostic capabilities and lack of complete medical records and health statistics. Instead, the available recorded diagnoses in vital health statistics relay on obvious illnesses, rather than on preexisting congenital defects present at birth that increase infant mortality and morbidity leading to the significant community problem $[1,16,17]$.

CMs are the fifth leading cause of years of potential life lost and a major cause of morbidity and mortality throughout children of the world [18]. Regardless of their clinical importance there are little studies conducted directly related the prevalence and predisposing risk factors [11, 19 - 22]. Consequence, the frequency, types, and patterns of birth defect need to be evaluated. Hence, the present study aimed to evaluate the prevalence and patterns of birth defects at birth in Southwestern Ethiopia.

\section{Methods}

\section{Study setting and period}

The study was carried out in six selected hospitals of three Zones in southwestern Ethiopia Namely: Jimma University Specialized, Shanan Gibe, Limmu Genet, Mattu Karl, Agaro and Nekemte hospitals; located in Jimma, llu Abba bori and East Wollega zones. The three zones are among the seventeen Zones in the west Oromia Regional State- the largest state in Ethiopia. The study was conducted retrospectively from September 2011 to December 2015. During this period a total of 45,951 deliveries were attended in the hospitals.

\section{Study and Sample Population}

The Sampling frame included all deliveries attended in selected hospitals insouthwestern region of Ethiopia during the period of September 2011 to December 2015.The sampling population involved all 
deliveries with birth defects that included both alive and still birth in the study hospitals.

\section{Study Design}

Institutions based cross-sectional study design was conducted insixselected hospitals with high caseload from the eight available hospitals in southwestern Ethiopia purposively. The two newly opened hospitals, Bedele and Gida Ayyana, were excluded because of the limited number of deliveries. Newborn baby care and management is same for all selected hospital which is according to the national guidelines. All new born babies were routinely screened for congenitally anomaly immediately after birth and just before discharge from hospitals. Physicians examine the health status of the newborns prior to getting discharged includes presence of congenital anomaly. Diagnosis is usually via physical examinations. Then, the midwifery on duty carry out the discharge as per the order and record the information nationally developed registration log book. One of the information on the log book is presence of congenital birth. We took the card number of newborns with congenital defect from the logbook and sought the card from card room and review according to the standard check list prepared for the purpose of data collection with the supervision of primary investigator. The data were collected by the trained midwifery, nursing and general practitioners. The collected data were checked for completeness and kept confidentially.

For a child born with minor or major birth defects, type of birth defect, socio-demographic variable such as age, educational status, income, residence, religion of the mother and obstetric history such as parity, gravida, history of abortion and stillbirth, Gestational age, birth weight were retrieved just to characterize the child.

\section{Data Analysis}

The collected data were cleaned, entered to EpiData Manager Version 2.0.8.56 computer software and the data was exported to SPSS software program version 22.0 for analyzes. Descriptive statistics like frequency was used to describe the study participants. BDs were classified using the International Classification of Diseases. The overall prevalence of birth defect was computed from total hospital births during the same period of time. An infant/fetus with more than one anomaly was counted once only based on the primary diagnosis. P-value less than 0.05 were considered as statistically significant between common types of $\mathrm{BD}$ and child of mothers' characteristics using Fisher exact test.

\section{Ethical Considerations}

Ethical approval was obtained from Institutional ReviewBoard of College of Health Sciences (IRB-CHS), Addis Ababa University research and postgraduate study office in collaboration with Jimma University institutional review board to conduct the research. The ethical and supportive letters were submitted to medical directors of all study hospitals to commence with data collection. Data collection began after permission was obtained from medical director of each study hospital. The data collected from medical record were kept confidentially. 


\section{Results}

From September 2011 to December 2015, 45,951 total deliveries were recorded. Out ofthese, 253 births were with a BD. 252 were with sex determined and 1 with ambiguous genitalia that was detected at birth. This makes the overall prevalence of BD 5.5 per 1000 births. The majority (92\%) of the mothers were younger than 35 years. About half of birth defect (49.6\%) occurred among mothers whose ages were between 25 - 35 years. $51.38 \%, 48.22 \%$ and $0.4 \%$ of children born with birth defect were males, females and ambiguous genitaliarespectively by their sex. About $63.1 \%$ of neonates with a BD were born as stillbirth. The majority of the mothers had no previous history of abortion and stillbirth, $92.5 \%$ and $93,3 \%$ respectively (table 1 ).

Table 1: Socio-demographic and Obstetricscharacteristics of mothers and child born with birth defects from September 2011 to December 2015, Southwest Ethiopia. 


\begin{tabular}{|c|c|c|c|}
\hline \multicolumn{2}{|l|}{ Characteristics } & Frequency (\%) & Percentage \\
\hline \multirow[t]{4}{*}{ Religion of the mothers } & Muslim & 115 & 45.6 \\
\hline & Orthodox & 33 & 13.1 \\
\hline & Protestant & 26 & 10.3 \\
\hline & Not mentioned & 78 & 31.1 \\
\hline \multirow[t]{4}{*}{ Age of the mothers } & $15-24$ & 105 & 41.7 \\
\hline & $25-35$ & 125 & 49.6 \\
\hline & $36-43$ & 12 & 4.8 \\
\hline & Missing & 10 & 4.0 \\
\hline \multirow[t]{2}{*}{ Onset of Labor } & Spontaneous & 202 & 80.2 \\
\hline & Induced & 50 & 19.9 \\
\hline \multirow[t]{2}{*}{ Mode of delivery } & Vaginal & 213 & 84.5 \\
\hline & Caesarean section & 39 & 15.5 \\
\hline \multirow[t]{2}{*}{ Sex of the newborn } & Male & 126 & 50.0 \\
\hline & Female & 126 & 50.0 \\
\hline \multirow[t]{2}{*}{ Status at birth } & Alive birth & 93 & 36.9 \\
\hline & Stillbirth & 159 & 63.1 \\
\hline \multirow[t]{2}{*}{ History of abortion } & Yes & 19 & 7.5 \\
\hline & No & 233 & 92.5 \\
\hline \multirow[t]{2}{*}{ History of stillbirth } & Yes & 17 & 6.7 \\
\hline & No & 235 & 93.3 \\
\hline \multirow[t]{4}{*}{ Gestational age } & Term & 139 & 55.2 \\
\hline & Preterm & 99 & 39.3 \\
\hline & Post term & 3 & 1.2 \\
\hline & Missing & 11 & 4.4 \\
\hline \multirow[t]{3}{*}{ Birth order } & $1-4$ & 116 & 46.0 \\
\hline & $5-9$ & 41 & 16.3 \\
\hline & Missing & 95 & 37.7 \\
\hline
\end{tabular}

Out of twenty-one different BDs that were recorded, neural tube defects (NTD) were (73.5\%), gastrointestinal defects were (13.4\%), musculoskeletal defects were $\mathrm{g}(11.1 \%)$ and genitourinary defects were (2\%) (Table 2). The major BDs identified during the study period were the NTDs which were found to be the most prevalent with frequency of $73.5 \%$ followed by gastrointestinal defects (13.4\%). Genitourinary defects were the least prevalent with the frequency of $2 \%$ followed by musculoskeletal (11.1\%) (table 2).

Table 2: Frequency of birth defects by sex among deliveries conducted from September 2011 to December 2015, Southwest Ethiopia. 


\begin{tabular}{|l|c|c|c|c|c|c|c|c|}
\hline \multirow{2}{*}{ Birth defects } & \multicolumn{2}{|l|}{ Male ( $\mathrm{n}=130)$} & \multicolumn{2}{l|}{$\begin{array}{l}\text { Female }(\mathrm{n}= \\
122)\end{array}$} & \multicolumn{2}{l|}{$\begin{array}{l}\text { Tmbiguous } \\
\text { genitalia (n=1) }\end{array}$} & \multicolumn{2}{l|}{ Total ( $=253)$} \\
\cline { 2 - 9 } & Frequency & $\%$ & Frequency & $\%$ & Frequency & $\%$ & Frequency & $\%$ \\
\hline $\begin{array}{l}\text { Neural tube } \\
\text { defects }\end{array}$ & 89 & 67.9 & 97 & 79.5 & 0 & 0 & 186 & 73.5 \\
\hline $\begin{array}{l}\text { Gastrointestinal } \\
\text { defects }\end{array}$ & 20 & 15.3 & 14 & 11.5 & 0 & 0 & 34 & 13.4 \\
\hline $\begin{array}{l}\text { Musculoskeletal } \\
\text { defects }\end{array}$ & 17 & 13.0 & 11 & 9.0 & 0 & 0 & 28 & 11.1 \\
\hline $\begin{array}{l}\text { Genitourinary } \\
\text { defects }\end{array}$ & 4 & 3.1 & 0 & 0 & 1 & 100 & 5 & 2.0 \\
\hline Total & 130 & 100 & 122 & 100 & 1 & 100 & 253 & 100 \\
\hline
\end{tabular}

Of the NTDs recorded, Anencephaly (33.9\%) and Hydrocephalus (33.3\%) were found to be the most frequent followed by spinal bifida (17.7\%). While, Microcephaly $(1.6 \%)$ and Craniorachischisis $(1.6 \%)$ were the least frequent (table 3).

Table 3:Frequency of neural defects among deliveries from September 2011 to December 2015 in Southwest Ethiopia.

\begin{tabular}{|l|c|c|c|c|c|l|}
\hline \multirow{2}{*}{ Neural tube defects } & \multicolumn{2}{|c|}{ Male $(\mathrm{n}=89)$} & \multicolumn{2}{l|}{ Female $(\mathrm{n}=97)$} & \multicolumn{2}{l|}{ Total (n=186) } \\
\cline { 2 - 7 } & Frequency & $\%$ & Frequency & $\%$ & Frequency & $\%$ \\
\hline Anencephaly & 25 & 28.1 & 38 & 39.2 & 63 & 33.87 \\
\hline Hydrocephalus & 32 & 17.2 & 30 & 30.9 & 62 & 33.33 \\
\hline Spinal bifida & 15 & 16.9 & 18 & 18.6 & 33 & 17.74 \\
\hline Meningomyelocele & 10 & 11.2 & 8 & 8.3 & 18 & 9.67 \\
\hline Encenphocele & 2 & 2.3 & 2 & 2.1 & 4 & 2.15 \\
\hline Microcephaly & 3 & 3.3 & 0 & 0 & 3 & 1.61 \\
\hline Craniorachischisis & 2 & 2.3 & 1 & 1.03 & 3 & 1.61 \\
\hline
\end{tabular}

Among gastrointestinal defects, the proportion of umbilical hernia, imperforate anus, Gastroschisis, Duodenal Atresia, congenital inguinal hernia and omphelocell was $35.3 \%, 26.5 \%, 17.7 \%, 8.8 \%, 8.8 \%$ and $2.9 \%$ respectively. Among gastrointestinal defects, the umbilical hernia was the most prevalent, $35.3 \%$ and omphelocell was the least frequent, $2.9 \%$ (table 4).

Among musculoskeletal defects, the proportion of Clubfoot, Cleft, cleft palate, both cleft lip and palate and Chest deformity was $36 \%, 24 \%, 20 \%, 16 \%$ and $4 \%$ respectively in decreasing order of their frequencies (table 5). 
Table 4: Frequency of gastrointestinal defects among deliveries from September 2011 to December 2015 in Southwest Ethiopia.

\begin{tabular}{|l|c|c|c|c|c|c|}
\hline \multirow{2}{*}{ Gastrointestinal defects } & \multicolumn{2}{|c|}{ Male $(\mathrm{n}=21)$} & \multicolumn{2}{l|}{ Female $(\mathrm{n}=13)$} & \multicolumn{2}{c|}{ Total (n=34) } \\
\cline { 2 - 7 } & Frequency & $\%$ & Frequency & $\%$ & Frequency & $\%$ \\
\hline Umbilical hernia & 3 & 14.3 & 9 & 69.2 & 12 & 35.3 \\
\hline Imperforate anus & 7 & 33.3 & 2 & 15.4 & 9 & 26.5 \\
\hline Gastroschisis & 5 & 23.8 & 1 & 7.7 & 6 & 17.7 \\
\hline Duodenal atresia & 2 & 9.5 & 1 & 7.7 & 3 & 8.8 \\
\hline Congenital inguinal hernia & 3 & 14.3 & 0 & 0 & 3 & 8.8 \\
\hline Omphelocell & 1 & 4.8 & 0 & 0 & 1 & 2.9 \\
\hline
\end{tabular}

Table 5. Frequency of musculoskeletaldefects among deliveries from September 2011 to December 2015 in Southwest Ethiopia

\begin{tabular}{|l|c|c|c|c|c|c|}
\hline \multirow{2}{*}{ Musculoskeletal defects } & \multicolumn{2}{|l|}{ Male (n=15) } & \multicolumn{2}{l|}{ Female (n=10) } & \multicolumn{2}{l|}{ Total (n=25) } \\
\cline { 2 - 8 } & Frequency & $\%$ & Frequency & $\%$ & Frequency & $\%$ \\
\hline Clubfoot-bilateral & 3 & 20.0 & 6 & 60.0 & 9 & 36.0 \\
\hline Cleft Lip & 4 & 26.7 & 2 & 20.0 & 6 & 24.0 \\
\hline Both cleftlip and palate & 3 & 20.0 & 2 & 20.0 & 5 & 20.0 \\
\hline Cleft palate & 4 & 26.7 & 0 & 0.0 & 4 & 16.0 \\
\hline Chest deformity & 1 & 6.7 & 0 & 0.0 & 1 & 4.0 \\
\hline
\end{tabular}

Genitourinary defects were the least frequent constituting $2 \%$ of the total major BDs identified in this study. Among genitourinary defects, the proportion of hypospadis, meatal stenosis, ambiguous genitalia were $50 \%, 37.5 \%$ and $12.5 \%$ respectively (table 6 ). The result showed that hypospadias was the most frequent and ambiguous genitalia were the least frequent among identified genitourinary defects. 
Table 6: Frequency of genitourinary defects among deliveries from September 2011 to December 2015in Southwest Ethiopia

\begin{tabular}{|l|c|c|c|c|c|c|}
\hline Genitourinary defects & \multicolumn{2}{|c|}{ Male (n=6) } & \multicolumn{2}{l|}{ Female (n = 1) } & \multicolumn{2}{l|}{ Total (n = 8) } \\
\cline { 2 - 8 } & Frequency & $\%$ & Frequency & $\%$ & Frequency & $\%$ \\
\hline Hypospadias & 4 & 66.7 & 0 & 0 & 4 & 50 \\
\hline Meatal stenosis & 2 & 33.3 & 1 & 100 & 3 & 37.5 \\
\hline Ambiguous genitalia & Null** & - & Null** & - & 1 & 12.5 \\
\hline
\end{tabular}

Null** Sex not signed

Of the twenty-one BDs identified in the present study, five types of BDs namely: Anencephaly (25.0\%), Hydrocephalus (24.6\%), Spinal bifida (13.1\%), Meningomyelocele (7.1\%), and Umbilical hernia (4.8\%) accounted about three-fourth (75\%) of all recorded birth defects (table 7 ).

Table 7: Types and frequency of birth defects recorded among deliveries from September 2011 to December 2015 in Southwestern Ethiopia. 


\begin{tabular}{|l|l|l|}
\hline Types of Birth defects & Frequency (\%) & Percentage \\
\hline Anencephaly & 63 & 25.0 \\
\hline Hydrocephalus & 62 & 24.6 \\
\hline Spinal bifida & 33 & 13.1 \\
\hline Meningomyelocele & 18 & 7.1 \\
\hline Umbilical hernia & 12 & 4.8 \\
\hline Imperforate anus & 9 & 3.6 \\
\hline Clubfoot-bilateral & 9 & 3.6 \\
\hline Cleft Lip & 6 & 2.4 \\
\hline Gastroschisis & 6 & 2.4 \\
\hline Both lip and palate cleft & 5 & 2.0 \\
\hline Hypospadias & 4 & 1.6 \\
\hline Cleft palate & 4 & 1.6 \\
\hline Encenphocele & 4 & 1.6 \\
\hline Duodenal atresia & 3 & 1.2 \\
\hline Microcephaly & 3 & 1.2 \\
\hline Meatal stenosis & 3 & 1.2 \\
\hline Craniorachischisis & 3 & 1.2 \\
\hline Congenital inguinal hernia & 3 & 0.4 \\
\hline Chest deformity & 1 & 0.4 \\
\hline Ambiguous genitalia & 1 & 1.2 \\
\hline Omphelocell & 1 & \\
\hline Total & 253 & \\
\hline
\end{tabular}

The association between the common types of defects and characteristics of the mothers and children were computed using Fisher's Exact Test. Only status of the child at birth (P-value $=0001)$, birth weight ( $P$ value $=0.0001)$ and gestational age $(P$-value $=0.0001)$ were found to be associated with types of birth defects.

\section{Discussion}

Birth defects, commonly called CA, occur at a rate of 1 in every 33 babies born. However, some are rather minor and others are major defects. In most cases, the major defects are the leading cause of high perinatal mortality and morbidity in developing countries as well as in developed countries [23]. 
According to World Health statistics, about 260,000 neonatal deaths worldwide are caused by congenital anomalies [10]. Accordingly, about $7 \%$ of all neonatal deaths, but varying from $5 \%$ in the South-East Asia Region to more than $25 \%$ in the European Region. It was also indicated that between-country variation, from 4\% (Bangladesh, Equatorial Guinea, Ethiopia, Liberia, Mali and Sierra Leone) and an estimated 8\% in China to $38 \%[10]$

In the present study, the overall proportion of BDs was $0.6 \%$, whereas in the study done in Addis Ababa, the capital city of Ethiopia, was found to be $2 \%$. The differences in proportion may be, because of theretrospective data from record reviews used in the present study which might have resulted in difficulty in capturing birth defects compared tothe primary data which wasused in the study in Addis Ababa.

In this study, a total of 253 birthdefects wereidentifiedfrom thetotal of 45951 deliveries duringthe study period. Theoverall prevalence rate of BDs in the present study was found to be 5.5 per 1000 totalbirths, where the NTDs were the most prevalent constituting to $73.5 \%$ of all the defects identified with the prevalence rate of $4.05 / 1000$ total births.

The previous study which was done in referral hospital of Northwestern Ethiopian was in line with the present study in that, the NTDs were the most prevalent typesofbirth defect with $32.5 \%$ [24]. According to the study done in china, the prevalence rate of NTD (20.1 per 10000 births) including anencephaly (6.9 per 10000), spinal bifida (10.6 per 10000), and encephalocele with 2.7 per 10000 was the highest, followed by congenital heart disease 17.1 per 10000 [3]. In the present study, the NTDs werewith prevalence rate of (40.5per 10000 child birth) with predominant types of NTDs namely: Anencephaly (13.7 per 10000), Hydrocephalus (13.2 per, 10000), Spinal bifida (7.2 per 10000) and Meningomyelocele (3.9 per 10000).The prevalence rate of NTD was twice ( 40.5 per 10000 total births, when compared with prevalence rate (20.1 per 10000) of NTDs of the study done in China. While the prevalence rate of spinal bifida (7.2 per 10000) slightly less than that of the prevalent rate of Spinal bifida (10.6 per 10000). The differences were may be due racial, geographical or environmental factors as well as genetic factors or multifactor inheritances.

In this study, Anencephaly and Hydrocephalus were the most common associated BDs with the frequency of $25 \%$ and $24.6 \%$ respectively. The other 1.43 per 1000 child births belongs to the rest ofBDsidentified in the present study indicating that the NTDs were the most prevalent. In line with our study, Abbey et el., 2017 [25] confirmed that the prevalence of major CA at the UPTH in the Niger Delta during the period 2011-2014 was 20.7 per 1,000 live births, with those of the central nervous system predominating at $27 \%$ of the total. In both studies, the NTD was more prevalent than other BDs revealing that NTD was the most prevalent throughout the world.

The study done in china identified that the prevalence rate of BD was 15.6 per 1000 [3]. On the other study, the overall prevalence of a major BD was 446.3 per 10,000 births [26]. In both studies, the BDs were seeming to be higher as compared to the present study. This may be because of differences in sociodemographic, registration and record keeping, racial or environmental factors. Unlike the present study where the NTDs were found to be the most prevalent defects, a study done in china indicated that 
septal defects ( 138.2 per 10,000) were the most prevalent followed by congenital hip dislocation ( 652 per 10,000) [26]. The study done in Addis Ababa and Amhara region by Mola et al., 2018 [19] revealed Orofacial defects (34.2\%) followed by NTDs (30.8\%) were the most frequent. In contrast, NTD (73.5\%) was the most prevalent followed by gastrointestinal defect (13.4\%) in this study. This may due to sociodemographic differences, ethnicity or study design.

The European Surveillance of CA (EUROCAT) reported that the prevalence of major BD in 2003-2007 was 239 per 10,000 births, of which $80 \%$ were delivered, $17.6 \%$ were terminated by induced abortion, $2.5 \%$ died after birth, and $2 \%$ were stillbirths $[26,27]$. This indicated that BDs were the major causes of infant morbidity and mortality being a major community burden. Finally, the male to female ratio in the present study was nearly $1: 1$ (51.8\% and $48.2 \%$ ) indicating those males are somewhat more affected than females. This is may be because of chromosomal abnormalities and a gene mutation commonly occurs in both male and female under similar conditions. However, this need further studies to justify the condition. In contrast to this study, there was a preponderance of females, with a female to male ratio of $1.4: 1$ as indicated in the study done in north - west Nigeria $[27,28]$ which is nearly in line with the present study. This is may be the environmental factors may influence the genetic pathways.

The limitation of the study was that it was hospital based retrospective recorded reviewed study. The outcome may not represent the actual prevalence of BDs in southwestern Ethiopian population. Hence, further community-based study that may represent the prevalence of BDs for the entire community of southwestern Ethiopian population need to be conducted.

\section{Conclusions}

The present study revealed that the prevalence of the BD at birth was found to be 5.48 cases per 1000 births. the prevalence of BD identified in the present study was found to be equally high as compared to other study. Among twenty-one BDs identified in this study, the NTDs were the most prevalent with the frequency of 4.05 cases per 1000 birth while all the rest constitute only a quarter of the total BDs identified with prevalence rate of 1.43 cases per 1000 births. The study also revealed that nearly equal proportions of BD occurred among males and females. The majority of the mothers who gave birth to BDs were younger than 35 years old. As the birth defects were founded to be leading cause of neonatal morbidity and mortality, planning, designing and implementation of prevention and management schemes for BDs are crucial.

\section{Abbreviations}

BD Birth defect

CA Congenital anomaly

CM Congenital malformation 
NTD Neural tube defect

WHO World Health Organization

\section{Declarations}

\section{Acknowledgements}

We would like to thank all medical wards of each study hospitals in southwestern Ethiopia who helped us in providing us the information necessary to the study. We would like to extend our sincere thanks to the Jimma University Specialized Hospital, Shanene Gibe hospital, Limu Genet hospital, Metu Karl hospital and Nekemte hospital in southwestern Ethiopia, who have allowed and helped us during data collection at their center. Our gratitude extends to our trained data collectors at each Hospitals of our study area. Our thanks also extend to the staffs of the department of Gynecology and Obstetrics of each hospital who had direct or indirect inputs for the successful accomplishment of the study.

\section{Author's Contributions}

Conceived the idea: SAG.

Designed the study: SAG, LD.

Conducted the study: SAG, GG, DA, LD.

Analyzed the data:SAG, GG, DA, LD.

Interpreted the results: SAG, GG, DA, LD.

Wrote the draft Manuscript: SAG.

Revised and edited the final manuscript: SAG, GG, DA, LD.

Approved the manuscript for submission: SAG, GG, DA, LD.

\section{Funding}

This study received fund (money) from Addis Ababa University and Jimma University for data collection only. The authors declare that they have received no funds for the publication of this manuscript and they have no external sources of fund for data collection and publications.

\section{Availability of data and materials}

The data set supporting this study are available in the manuscript.

\section{Ethical Approval and consent participants}


Ethical approval was obtained from Institutional Review Board of College of Health Sciences (IRB-CHS), Addis Ababa University research and postgraduate study office in collaboration with Jimma University institutional review board to conduct the research. The data collection began after permission was obtained from medical director of each study hospitals upon submission of ethical and supportive letters each medical director. As the data collected from medical record, the study participants were not present during data collection.

\section{Consent for publication}

Not applicable.

\section{Competing interests}

The authors declare that they have no competing interests.

\section{Author details}

${ }^{1 *}$ Department Anatomy, School of Medicine, College of Health Sciences, Addis Ababa University, Ethiopia.

${ }^{1}$ Department Anatomy, School of Medicine, College of Health Sciences, Addis Ababa University, Ethiopia.

${ }^{2}$ Department of Gynecology and Obstetrics, College of Public Health and Medical Sciences, Jimma University, Ethiopia.

${ }^{3}$ Department of Epidemiology, College of Public Health and Medical Sciences, Jimma University, Ethiopia.

\section{References}

1. Butt F., Shahzad R. and Pasha I. Pattern and outcome of congenital anomalies and maternal risk factor association. Biomedica. 2013; 29: 234 - 240.

2. Victor B. P. Preventing congenital anomalies in developing countries. Community Genet. 2002; 5:6169.

3. Zhang X., Li.S, Wu S.,Hao X., GuoS., Suzuki K., Yokomichi H. and Yamagata Z. Prevalence of birth defects and risk factor analysis from a population based survey in Inner Mongolia, China. BioMedical Centre. Pediatrics. 2012; 12:125.

4. Ekwere O. E., Rosie M., BobPaul A., Bamidele J., Olorunleke O. and Sunday P. A retrospective study of congenital anomalies presented at tertiary health facilities in Jos, Nigeria. International Journal of Pharmaceutical Science Invention. 2011; 3:24 - 28.

5. Ahmadzadeh A., Safikhani Z., Abdulahi M. and Ahmadzadeh A. Congenital malformations among live births at Arvand Hospital, Ahwaz, Iran. Pakistan Journal of Medical Sciences. 2008; 24(1): 33-37.

6. The sixty-third world assembly of the health. http://apps.who.int/gb/ebwha/pdf_files/WHA63REC1/WHA63_REC1-en.pdf. Geneva. 
7. Shawky M. and Sadik D. I. Congenital malformations prevalent among Egyptian children and associated risk factors. The Egyptian Journal of Medical Human Genetics. 2011; 12: 69-78

8. Delport S.D., Christianson A. L., van den Berg H. J. S., Wolmarans L. and Gericke G. S. Congenital anomalies in black South African liveborn neonates at an urban academic hospital. South African Medical Journal. 1995; 85: 11-15.

9. Parmar A., Rathod S.P., Patel S. V. and Patel S.M. A Study of congenital anomalies in newborn. National Journal of Integrated Research in Medicine. 2010;1(1): 13 - 17.

10. Rizk F., Salameh P. and Hamadé A. Congenital anomalies: Prevalence and risk factors. Universal Journal of Public Health. 2014; 2(2): 58-63.

11. Mohamed A. El K., Ehab A. Al B. and Ibrahim L. Pattern of congenital anomalies in newborn: A hospital-based study. Pediatric Reports. 2013; 5(5):20 -23.

12. Taboo Z.A. Prevalence and risk factors for congenital anomalies in Mosul City. The Iraqi Postgraduate Medical Journal. 2012; 22(2): 140 -146.

13. Amany M. A., Shadia A., Azza A. A. and Hassan M. G. Assessment of risk factors for fetal congenital anomalies among pregnant women at Cairo University Hospitals. Journal of American Science. 2011; 7(12):899 -908.

14. Naeimeh T., Katayon Y. and Nazila N. The Prevalence of congenital malformations and its correlation with consanguineous marriages. Oman Medical Journal. 2010; 25:37-40.

15. Vinceti M., Malagoli C., Rodolfi R., Astolfi G., Rivieri F., Fiorini S., Muzii M., Campagna A., Bergomi M. and Vivoli G. Prevalence at birth of congenital anomalies in a population living around a modern municipal solid waste inciderator. Epidemiology. 2006; 17(6): 272 -273.

16. Ekwere O. E., Rosie M., BobPaul A., Bamidele J., Olorunleke O. and Sunday P. A retrospective study of congenital anomalies presented at tertiary health facilities in Jos, Nigeria. International Journal of Pharmaceutical Science Invention.2011; 3:24 - 28.

17. Waqas J., Farooq A., Taimoor J. andMuhammad S. M. Prevalence of gross congenital malformations at birth in the neonates in a Tertiary Care Hospital.Epidemiology. 2009; 3(1):47 - 50.

18. Flores AL, Vellozzi C, Valencia D, and Sniezek J. (). Global Burden of Neural Tube Defects, Risk Factors, and Prevention. Indian J Community Health. 2014; 26(1): 3-5.

19. Taye M., Afewor M., Fantaye W., Diro E., and Worku A. Factors associated with congenital anomalies in Addis Ababa and the Amhara Region, Ethiopia: a case-control study. BMC Pediatrics. 2018; $18: 1$ 12.

20. Victor B. P. Preventing congenital anomalies in developing countries. Community Genet. 2002; 5:6169.

21. Golalipour M. J., Najafi L., Keshtkar A. A. Prevalence of Anencephaly in Gorgan, Northern Iran. Arch Iran Med. 2010; 13 (1): 34 - 37.

22. Neumann P.E., Frankel W.N., Letts V.A., Coffin J.M., Copp A.J. and Bernfield M. Multifactorial inheritance of neural tube defects: Localization of the major gene and recognition of modifiers in ct 
mutant mice. Nature Genetics. 1994; 6(4):357-362.

23. Rosano, 2000Rosano, A., Botto, L.D., Botting, B. andMastroiacovo, P. Infant mortality and congenital anomalies from 1950 to 1994: An international perspective. Journal of Epidemiology and Community Health, 2000; 54(9), 660-666.

24. Adane F and .Seyoum G. Prevalence and associated factors of birth defects among newborns at referral hospitals in Northwest Ethiopia. Ethiop. J. Health Dev.2018; 32 (3):1 - 7.

25. Abbey , OloyedeO. A , BasseyG., KejehB., OtaigbeB. E., OparaP. I , EnehA. U. and Akan C.I.Prevalence and pattern of birth defects in a tertiary health facility in the Niger Delta area of Nigeria.Int $\mathrm{J}$ Women Health. 2017; 9: 115-121.

26. Jung-KeunK., DirgaK.L.,Hwan-Cheol K., and Jong-Han L. Trends in the Prevalence of Selected Birth Defects in Korea.Int J Environ Res Public Health. 2004; 15(5): 1-13

27. NnadiD.CandSinghS.Theprevalence of neural tube defects in North-West Nigeria. Saudi Journal for Health Sciences. 2017; 5 (1): 6 - 10.

28. Singh S, Chukwunyere DN, Omembelede J, Onankpa B. ). Foetal congenital anomalies: An experience from a tertiary health institution in north-west Nigeria (2011-2013). Niger Postgrad Med J.2015; 22:174-8 